\title{
Clinical Approach to Parkinson's Disease: Features, Diagnosis, and Principles of Management
}

\author{
João Massano ${ }^{1,2}$ and Kailash P. Bhatia ${ }^{1}$ \\ ${ }^{1}$ Sobell Department of Motor Neuroscience and Movement Disorders, Institute of Neurology, \\ University College London, Queen Square, London, United Kingdom \\ ${ }^{2}$ Movement Disorders and Functional Surgery Unit, Department of Neurology Hospital de São João \\ and Faculty of Medicine University of Porto, Porto, Portugal \\ Correspondence: k.bhatia@ion.ucl.ac.uk
}

Parkinson's disease (PD) is one of the most common neurodegenerative disorders. The condition causes a heavy burden both on those affected, as well as their families. Accurate diagnosis is critical and remains founded on clinical grounds as no specific diagnostic test is available so far. The clinical picture of PD is typical in many instances; however, features distinguishing it from other disorders should be thoroughly sought. Monogenic forms of PD also have some distinctive characteristics in many cases. This text is a roadmap to accurate diagnosis in PD, as it approaches clinical features, diagnostic methodology, and leading differential diagnoses. Therapeutic issues are also briefly discussed.

\begin{abstract}
Nearly 200 years have passed since the publication of James Parkinson's succinct observations in An Essay on the Shaking Palsy (Parkinson 1817, reprinted in Parkinson 2002; for more details on the history of PD see the text by Goetz 2011). Remarkably, the original clinical description of the disease remains a landmark reference, especially with regard to the motor features. Parkinson's disease (PD), as Jean Martin Charcot called it a few decades later (Lees 2007; Lanska 2010), is a common and often disabling disorder seen in people from all races and geographical locations, with clinical signs emerging also in a wide age range, including the young (Marsden 1994; Tolosa et al. 2006; Lees et al. 2009).
\end{abstract}

The epidemiological figures pertaining to $\mathrm{PD}$ are not accurately determined, as different studies were variable in diagnostic criteria, methodology, and study population. A prevalence of $\sim 1 \%-2 \%$ in the population older than $60-65$ $\mathrm{yr}$, or $0.3 \%$ in the general population, is now commonly accepted (de Lau and Breteler 2006; Hirtz et al. 2007; Alves et al. 2008), with prevalence rates ranging from 65.6 to 12,500 per 100,000 population (von Campenhausen et al. 2005). In 2005, more than 4 million PD patients existed in the world (Dorsey et al. 2007). Annual incidence rates range from 8.6 to 19 per 100,000 (Twelves et al. 2003; de Lau and Breteler 2006; Alves et al. 2008). PD is the second most common neurodegenerative disorder after Alzhei-

Editor: Serge Przedborski

Additional Perspectives on Parkinson's Disease available at www.perspectivesinmedicine.org

Copyright (C) 2012 Cold Spring Harbor Laboratory Press; all rights reserved; doi: 10.1101/cshperspect.a008870

Cite this article as Cold Spring Harb Perspect Med 2012;2:a008870 
mer's disease, with a male-to-female ratio of about 3:2 in most studies (de Lau and Breteler 2006; Alves et al. 2008). It occurs infrequently under 40 years of age, with early onset increasing the probability that genetic causes might be involved (de Lau and Breteler 2006; Schrag and Schott 2006).

The cause of PD is unknown, although complex interactions between genetic and environmental factors are probably involved. Various risk factors have been found for sporadic PD, including exposure to pesticides and other toxics, positive family history, and oophorectomy, but age remains the most important one documented so far (de Lau and Breteler 2006; Elbaz and Moisan 2008; Bronstein et al. 2009). Thus, disease prevalence is expected to increase dramatically in the next decades as the population ages, which might raise serious issues at a worldwide level with regard to social security and health care systems. This might be particularly true for developing countries such as China or India (Dorsey et al. 2007). Conversely, there have been data showing that protective factors might exist, the most robust association with smoking, but also coffee or black tea drinking, and possibly nonsteroidal anti-inflammatory drugs (Elbaz and Moisan 2008; Bronstein et al. 2009; Gao et al. 2011). In this regard, an interesting finding concerns high uric acid levels, which seem to protect from PD, and are apparently also associated with decreased rates of disease progression (Elbaz and Moisan 2008; Schlesinger and Schlesinger 2008).

\section{CLINICAL FEATURES}

\section{Motor Symptoms}

From the motor standpoint PD is characterized by a clinical syndrome universally known as parkinsonism, which includes four cardinal features: bradykinesia, rest tremor, rigidity, and postural and gait impairment. One should bear in mind that these are not always observed in every patient, at least in a given time frame.

1. Bradykinesia refers to slowness of movements with a progressive loss of amplitude or speed during attempted rapid alternating movements of body segments (Marsden 1982; Edwards et al. 2008a; Jankovic 2008; Rodríguez-Oroz et al. 2009). It is crucial to distinguish true bradykinesia from simple slowness, which is frequently seen in patients with decreased muscle power ( paresis), spasticity, or reduced motivation (e.g., depression). In fact, failing to acknowledge this is a major source of misdiagnosis. Clinically, bradykinesia can be assessed by asking the patient to perform some repetitive movements as quickly and widely as possible, namely, opening and closing the hand, tapping thumb and index fingers, or tapping the foot on the ground (see online Movies 1 and 2 at www.perspectivesinmedicine.org). The examiner must pay attention to the emergence of progressive slowness and/or loss of amplitude, which might ultimately bring the movement to full arrest (freezing, see online Movie 2). Bradykinesia can also be searched for globally by observing the patient's spontaneous movements while sitting, standing up from a chair, or walking (see online Movies 3 and 4 at www.perspectivesinmedicine.org). Other clinical displays of bradykinesia are hypomimia (decreased facial expression and eye blinking, termed "poker face" in milder stages, see online Movie 2), hypophonia (softer voice), micrographia (progressively smaller handwriting), and difficulty swallowing.

2. Rest tremor (sometimes also called parkinsonian tremor) is a rhythmic oscillatory involuntary movement that comes about when the affected body part is relaxed and supported by a surface, thus removing the action of gravitational forces (Deuschl et al. 1998; Bain 2007; Edwards et al. 2008b). It vanishes with active movement, and typically can reappear after a few seconds when the arms are held outstretched (reemergent tremor). In $\mathrm{PD}$, rest tremor frequency is usually in the low to mid-range $(3-6 \mathrm{~Hz})$, whereas the amplitude is quite variable, from less than $1 \mathrm{~cm}$ to $>10 \mathrm{~cm}$ wide (see online Movies 1, 3, 5, and 6 at www.perspectivesinmedicine.org). The most distinguishing tremor in this dis- 
order is the so-called "pill-rolling" type, a visual portrayal resulting from the simultaneous rubbing movements of thumb and index fingers against each other (see online Movie 1). Other forms of tremor movements can be seen, such as finger flexion-extension or abduction-adduction. Tremor can also be present in the lower limbs, jaw (see online Movie 5), and tongue. Head tremor is not typical of PD; in fact, it should prompt careful diagnostic reconsideration. An additional form of tremor, postural (e.g., occurs immediately on stretching out the arms), faster $(6-8 \mathrm{~Hz})$, can be occasionally seen in PD, but this is noncontributory to the diagnosis. In clinical practice, tremor is best observed while the patient is focused on a particular mental task (e.g., countdown from 100 with eyes closed), which facilitates limb muscle relaxation.

3. Rigidity refers to an increased muscle tone felt during examination by passive movement of the affected segment (limbs or neck), involving both flexor and extensor muscle groups (Edwards et al. 2008a; Jankovic 2008; Rodríguez-Oroz et al. 2009). This resistance is felt throughout the full range of movement, and does not increase with higher mobilization speed, which distinguishes it from spasticity owing to upper motor neuron lesions. When resting tremor coexists the classical " $\operatorname{cog}$ wheel rigidity" can be felt during passive limb mobilization, especially in the wrist. Rigidity in the examined segment is very typically increased by voluntary movement of other body parts (Froment's maneuver), and this is a useful way to detect mild rigidity in many cases.

4. Postural and gait impairment. Parkinsonian patients tend to adopt a stooped posture (see online Movie 7 at www.perspectivesinmedicine.org), owing to the loss of postural reflexes, a major contributor to falls (Edwards et al. 2008a; Jankovic 2008; Sethi 2008). In some cases extreme anterior truncal flexion may supervene (camptocormia). Parkinsonian gait is slow, occurs on a narrow base, and is characterized by short shuffling steps, which gives the observer the impression that the patient is chasing his own center of gravity. There is decreased arm swing, turning around is slow and performed with multiple small steps (see online Movies 3 and 5), whereas freezing of gait can occur (see online Movie 8 at www.perspectivesinmedicine.org), especially in crowded or narrow places (Edwards et al. 2008a; Sethi 2008). In certain circumstances there is festination, in which a very fast succession of steps is seen, with the patient at times only able to stop when meeting some sort of obstacle. Walking and turning becomes more difficult or even impossible in parkinsonian patients if an additional cognitive load is imposed (e.g., dual tasking) (Sethi 2008; Spildooren et al. 2010; Plotnik et al. 2011). Clinically, one should observe posture and gait both on an open corridor and while passing through narrow doorways or spaces. The "pull test" is performed in order to assess postural stability; the examiner stands behind the supine patient who is previously warned of the "pull" applied to his/her shoulders, then allowing him/her to step back in order to regain balance-some patients will fall without any sort of postural response.

\section{Nonmotor Symptoms and the Premotor Phase of PD}

PD has been traditionally regarded as a motor disorder, perhaps because the original account of the clinical features emphasized these symptoms, while failing to recognize the important nonmotor aspects of the disease. In addition, motor symptoms often meet the eye straightaway, even for untrained observers. However, in recent years there has been an increasing interest in nonmotor symptoms of PD (Table 1), because their recognition is useful for diagnostic purposes, but also because they are a major source of deterioration in quality of life, and warrant specific management (Poewe 2008; Chaudhuri and Schapira 2009; Lim et al. 2009; Gallagher et al. 2010).

The work from Braak and coworkers showed that disease symptoms correlate with the extension of the pathology affecting the nervous sys- 
J. Massano and K.P. Bhatia

Table 1. Nonmotor symptoms in Parkinson's disease

Neuropsychiatric features
Apathy
Anxiety, panic attacks
Mood disorders, especially depression
Hallucinations, illusions, delusions
Cognitive deterioration, ranging from mild
impairment to dementia

Dysautonomia

Orthostatic hypotension

Constipation

Urinary dysfunction (urgency, retention)

Sexual dysfunction

Excessive sweating

Seborrhea

Sialorrhea (i.e., drooling, also attributable to decreased swallowing movements)

\section{Sleep disorders}

Insomnia

REM behavior disorder

Restless legs syndrome

Periodic limb movements in sleep

Excessive daytime sleepiness

\section{Sensory dysfunction}

Hyposmia (i.e., loss of sense of smell)

Decreased visual contrast and color discrimination

Decreased visual motion perception

Abnormal sensations, such as paresthesias (i.e., tingling)

\section{Pain}

\section{Fatigue}

Data from Silva et al. 2005; Emre et al. 2007; Poewe 2008; Castelo-Branco et al. 2009; Chaudhuri and Schapira 2009; Lim et al. 2009; and Gallagher et al. 2010.

Abbreviation: REM, rapid eye movement.

tem (Braak et al. 2003; Hawkes et al. 2010). Because of long-term pathological progression, some of these nonmotor features may be present before any of the classical motor signs are noticeable, sometimes for years or decades, which confers them potential diagnostic utility in early disease stages, such as hyposmia, rapid eye movement (REM) behavior disorder, constipation, and depression (Lim et al. 2009; Tolosa et al. 2009; Hawkes et al. 2010; Savica et al. 2010; Schapira and Tolosa 2010). Some patients will have unexplained shoulder pain or fatigue be- fore overt motor symptoms emerge. On the other hand, features like dementia and hallucinations occur late in the course of disease, which is useful for distinguishing PD from other disorders. Mild cognitive dysfunction is apparent in many cases from early stages, but recent data has shown that frank dementia will occur in $>80 \%$ of patients after 20 years of disease (Healy et al. 2008).

\section{DIAGNOSIS OF PD AND DIFFERENTIAL DIAGNOSIS}

\section{How to Diagnose PD}

The diagnosis of PD is still largely a clinical one, as there is no definitive test able to confirm the diagnosis during life, with the exception of gene testing in a reduced number of cases. PD is a disease combining clinically defined parkinsonism with specific pathological findings, namely, dopaminergic neuron loss in the region of substantia nigra pars compacta, as well as the presence of intraneuronal Lewy bodies (Marsden 1994; Lees et al. 2009), although there are a few notable exceptions to this with regard to the pathological diagnosis. From a practical perspective, the first step for the diagnosis of PD is careful history taking. Thorough questioning of the patient and family should be performed, trying to define which symptoms emerged and their sequence, as well as perceived anatomical involvement. Inquiry about the presence of premotor symptoms including sleep-related REM sleep behavior, loss of smell, and constipation can be helpful if present. Drug intake history, both past and present, especially concerning drugs able to cause parkinsonian symptoms, is paramount. Likewise, possible exposure to environmental toxics should also be searched for (e.g., manganese in welders). Past and present medical disorders should be systematically recorded. Family history is also an important stage, and should include neurological disorders in other family members, as well as inquiry about ethnic ancestry as monogenic forms of PD are more prevalent in some (e.g., Ashkenazi Jewish and North African Arabs who have a higher frequency of LRRK2 genetic PD). 
Clinical Approach to Parkinson's Disease

Clinical examination follows: this should be thorough and systematic. A note should be made if there is a typical resting pill-rolling tremor and bradykinesia. If this is present in an asymmetric fashion then it is almost pathognomonic for PD. Notably, PD parkinsonism is usually different from that seen in other parkinsonian disorders, because it emerges and progresses asymmetrically (e.g., one side of the body is more affected), with gait and balance being affected later in the course of disease. Moreover, it is important to confirm that parkinsonian features are the only clinical signs-implying that pyramidal, sensory, and cerebellar deficits should be excluded, as well as dementia (early in disease course), and other movement disorders (e.g., chorea, myoclonus, tics, unexpected type of tremor), with the exception of dystonia as this can be seen in some cases, particularly the youngonset forms of PD. Eye movements in PD should be full range and display normal latency (e.g., immediate movement after command), speed, and accuracy. Some findings should raise doubts about the diagnosis of $\mathrm{PD}$, and other disorders should be considered instead, whenever any of these are observed (Table 2). In some cases who have received levodopa treatment, the presence of typical limb choreiform dyskinesias is also a useful sign suggesting IPD.

In typical circumstances, a restricted number of investigations are necessary to establish the clinical diagnosis of PD. A few treatable conditions, which might cause asthenia or "slowness" (not true bradykinesia), such as anemia and hypothyroidism, should be ruled out by appropriate laboratory testing. Other specific suspicions guide further investigations. Brain structural imaging, either by computed tomography $(\mathrm{CT})$ or magnetic resonance imaging (MRI) should always be performed; where available the latter is preferred, because some positive findings occasionally reveal other diagnostic entities (Massano et al. 2008; Sitburana and Ondo 2009). CT scan should be used whenever calcium deposits are being searched for (e.g., Fahr's disease). Dopamine functional imaging might be considered to confirm that degenerative parkinsonism is the cause of symptoms. Positron emission tomography (PET) with fluoro-
Table 2. "Red flags" for an incorrect diagnosis of PD

Absence of symptom asymmetry

Severe axial or lower limb involvement, especially in early stages

Frequent falls, especially in early stages

Fast disease progression (e.g., Hoehn and Yahr stage 3 in less than 3 years)

Eye movement disorders (e.g., supranuclear palsy, dysmetric or slow saccades)

Other unexpected movement disorder, such as myoclonus, tics, and chorea

Pyramidal or cerebellar dysfunction

Bulbar or pseudobulbar features

Parietal associative sensory disturbances (agraphesthesia, astereognosis)

Apraxia

Alien limb

Severe cognitive deterioration or psychosis early in disease course

Marked autonomic dysfunction in early stages Insufficient clinical benefit gained from adequate trial of levodopa or apomorphine

The features listed here are not typical of Parkinson's disease, and should raise suspicion about alternative diagnoses. Hoehn and Yahr staging is described in Goetz et al. 2004.

dopa is one of the technologies available, but the costs and limited accessibility make it difficult to use. In this regard, dopamine transporter (DAT) imaging with single-photon emission CT (DAT-SPECT) is a very useful approach, because it is sensitive for the detection of presynaptic dopaminergic neuron degeneration in the striatum (Kägi et al. 2010a). None of these methods is able to distinguish PD from other causes of degenerative parkinsonism, but presynaptic dopamine imaging is normal in essential tremor, dystonic tremor, drug-induced, psychogenic tremor, and psychogenic parkinsonism (for more on details on functional imaging in PD please refer to the text by Niethammer et al. 2012). In appropriate circumstances, genetic testing might be considered; whenever a pathogenic mutation is found, a definitive diagnosis of PD is achieved in vivo. Another way of sanctioning the diagnosis of PD is through the observation of the clinical benefit gained from an acute challenge of oral levodopa or subcutaneous apomorphine, which should markedly 
improve the clinical symptoms-otherwise, other diagnostic possibilities should be considered, although some PD patients will only respond to long-term high doses of levodopa. Dopaminergic drugs confer a sustained benefit in PD. The UK Parkinson's Disease Society Brain Bank clinical diagnostic criteria (the Queen Square Brain Bank criteria) are routinely used to make the diagnostic process as objective and accurate as possible. Three major steps are required for the diagnosis of PD, as depicted in Table 3.

Currently, MRI is preferred over CT, and family history is not regarded as an exclusion criterion, because a number of Mendelian forms of PD have been described.

\section{Differential Diagnosis}

PD can be confused with many disorders, and diagnostic accuracy improves with increasing clinical experience. The entities most commonly confused with PD are (Edwards et al. 2008c; Jankovic 2008; Lees et al. 2009)

1. Vascular parkinsonism: In this situation parkinsonian symptoms predominate in the lower limbs, and gait tends to be quite affected, hence the designation "lower body parkinsonism"; rest tremor is uncommon. Other signs of brain vascular lesion might be present, such as spasticity, hemiparesis, and pseudobulbar palsy, whereas response to levodopa is usually scarce (Winikates and Jankovic 1999; Edwards et al. 2008c; Lees et al. 2009; Kalra et al. 2010). Structural brain imaging is especially important to rule out or support this diagnosis.

2. Drug-induced parkinsonism (DIP): Parkinsonian signs tend to present symmetrically and a coarse postural tremor is often present. Other drug-induced disorders might be present, such as orolingual dyskinesias, tardive dystonia, or akathisia, especially in those cases in which the culprit drug is an antipsychotic. For the diagnosis of DIP it is important that symptoms have emerged after the drug has been introduced (Alvarez and Evidente 2008). In true DIP symptoms improve
Table 3. The UK Parkinson's Disease Society Brain Bank clinical diagnostic criteria

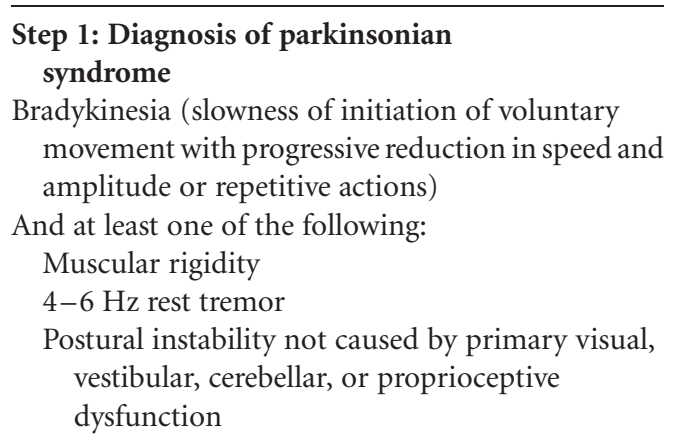

\section{Step 2: Exclusion criteria for Parkinson's disease}

History of repeated strokes with stepwise progression of parkinsonian features

History of repeated head injury

History of definite encephalitis

Oculogyric crises

Neuroleptic treatment at onset of symptoms

More than one affected relative ${ }^{\mathrm{a}}$

Sustained remission

Strictly unilateral features after 3 years

Supranuclear gaze palsy

Cerebellar signs

Early severe autonomic involvement

Early severe dementia with disturbances of memory, language, and praxis

Babinski sign

Presence of a cerebral tumor or communicating hydrocephalus on CT scan

Negative response to large doses of levodopa (if malabsorption excluded)

MPTP exposure

\section{Step 3: Supportive positive criteria of Parkinson's} disease

Three or more required for diagnosis of definite Parkinson's disease:

Unilateral onset

Rest tremor present

Progressive disorder

Persistent asymmetry affecting the side onset most

Excellent response $(70 \%-100 \%)$ to L-dopa

Severe levodopa-induced chorea

Levodopa response for 5 years or more

Clinical course of 10 years or more

Hyposmia

Visual hallucinations

\footnotetext{
${ }^{\text {a}}$ This criterion is no longer used (Hughes et al. 1992;
} Litvan et al. 2003; Lees et al. 2009). 
markedly or remit a few months after complete drug withdrawal, but symptoms remain at least partially in those patients with a concomitant cause for parkinsonism (e.g., PD).

3. Tremor disorders: Essential tremor (ET) is often confused with tremulous PD (Schrag et al. 2000; Jain et al. 2006), but careful observation will result in a correct diagnosis, because the characteristics of ET are quite distinct; it is a largely symmetric postural or kinetic hand tremor reaching a frequency of up to $12 \mathrm{~Hz}$, infrequently observed at rest, and unaccompanied by any parkinsonian signs or abnormal posturing (Bain et al. 1994; Deuschl et al. 1998; Edwards et al. 2008b). In a large series, Bain and coworkers (1994) found that autosomal-dominant inheritance was archetypal, with the mean age at onset of tremor being 15 years old; half of the patients displayed alcohol responsiveness, and head tremor was mild when present. A few interesting and mind provocative reflections about ET have recently been published (Quinn et al. 2011). Another group of tremor patients frequently misdiagnosed as PD were more recently characterized (Schneider et al. 2007; Schwingenschuh et al. 2010)_These patients have SWEDDs ("scans without evidence of dopaminergic deficits"), hence named owing to the fact that DAT imaging is normal, thus ruling out striatal presynaptic degeneration. In these patients, tremor at rest or asymmetry are frequent, as well as head tremor, but no true akinesia is seen, although decreased arm swing may be apparent. This group shows clinical and electrophysiological characteristics resembling dystonia, which should be actively searched for clinically (Schneider et al. 2007; Schwingenschuh et al. 2010).

4. Dementia with Lewy bodies (DLB): Dementia is the fundamental feature of this disorder, whereas parkinsonism is seen either early or along the course of the disease, in striking contrast with PD. These patients, usually elderly, suffer from marked daily fluctuations in alertness and cognition, as well as very detailed and colorful visual hal- lucinations, involving human figures (children is a very typical motif) and animals. Other features frequently seen are REM sleep behavior disorder, extreme sensitivity to the effects of neuroleptic drugs, and dysautonomia (Geser et al. 2005; Weisman and McKeith 2007). Because of common clinical and pathological findings, a lively debate still revolves around the fact that DLB and PD could belong to the same spectrum of a common disease or, in contrast, represent truly separate disorders.

5. Multiple system atrophy: This is one of the most common causes of degenerative parkinsonism, with age at onset of symptoms usually in the late 6 th or early 7 th decades. Classically, patients present with a core combination of dysautonomia, cerebellar features, and parkinsonism; in most patients the latter predominates, except in Japanese populations. A jerky postural tremor is frequently seen, as well as pyramidal signs, such as generalized hyperreflexia and extensor plantar reflexes. Parkinsonism will respond to levodopa in up to roughly a third of patients, but this is usually a suboptimal and short-lived benefit (Edwards 2008c; Gilman et al. 2008; Stefanova et al. 2009). Other suggestive features of this disorder are severe dysarthria or dysphonia, orofacial dystonia, marked antecollis, and inspiratory sighing (Gilman et al. 2008; Stefanova et al. 2009). MRI may help in the diagnosis, by disclosing findings such as cerebellar and pontine atrophy, the "hot cross bun" sign, or a hypertense rim surrounding the putamen in T2-weighted sequences (Massano et al. 2008; Sitburana and Ondo 2009).

6. Progressive supranuclear palsy: The classical phenotype (Richardson syndrome, RS) will be hardly confused with PD, as patients present with a largely symmetric akinetic-rigid syndrome, with predominant axial involvement, including impairment of gait and balance, with falls occurring as early as the first year of symptoms. Tremor is infrequently seen in these patients. Other typical signs of RS are vertical gaze supranuclear palsy (only slowing of vertical saccades is apparent 
in early stages), pseudobulbar symptoms, retrocollis, and continuous activity of the frontalis muscle, with eyes permanently wide open (e.g., "staring eyes"). Frontal-subcortical cognitive deficits are usually evident. Levodopa is usually of no benefit (Warren and Burn 2007; Williams and Lees 2009). However, other patients present with a parkinsonian syndrome resembling PD: symptoms are asymmetric, at times with rest tremor, with few axial involvement, delayed onset, or no eye movement disorder, and displaying levodopa responsiveness, even if partial. This syndrome has been called PSP-P ("PSP-parkinsonism") and survival is longer than in RS (Williams et al. 2005).

7. Fragile X-tremor ataxia syndrome (FXTAS): This is a late-onset (usually $>50$ years of age) neurodegenerative disorder seen in patients (especially men) who carry an abnormal number of CGG repeats in the FMR1 gene, in the premutation range (55-200 repeats). Core symptoms are cerebellar gait ataxia and postural/intention tremor, variably accompanied by parkinsonism, dysautonomia, cognitive decline of the frontal type, and peripheral neuropathy. Disease progression is usually slow. Parkinsonian symptoms resembling the classical picture of PD have been described. Women carrying the premutation tend to display mitigated symptoms, as well as premature ovarian failure and menopause. MRI may be a useful adjunct to the diagnosis, as many patients will show T2 hyperintensities in the middle cerebellar peduncles ("MCP sign"), especially affected males. Confirmation of diagnosis is achieved through molecular testing. Children in the family of those affected with FXTAS may have the classical fragile-X syndrome, owing to meiotic repeat expansion to the full mutation range (Berry-Kravis et al. 2007; Jacquemont et al. 2007).

Many other parkinsonian disorders have been described (Table 4), and some of them are at times confused with PD, although they tend to present specific clinical features, frequently with complex phenotypes.

\section{HEREDITARY FORMS OF PARKINSON'S DISEASE AND THEIR CLINICAL FEATURES}

A small but significant number of PD patients have a family history compatible with Mendelian autosomal inheritance $(10 \%-15 \%)$, either dominant or recessive. Many of these are classified as young-onset ( $<40 \mathrm{yr}$ ) or juvenile-onset PD ( $<21$ yr) (Schrag and Schott 2006). A number of levodopa-responsive parkinsonian syndromes have been described and linked to a specific locus or gene in the last few years, and some of them have been classified as PARK syndromes (Gasser 2007; Klein et al. 2009). Some of these denote true PD, whereas others represent more complex phenotypes and dissimilar diseases. Only the former group will be briefly approached here, as the clinical phenotype may be a useful pointer for the diagnosis in daily practice, guiding subsequent molecular testing. For more details on the genetics of PD please refer to Klein and Westenberger (2012).

1. Autosomal-dominant (AD) PD:

a. PARK1/PARK4 (gene SNCA, $\alpha$-synuclein): Mean age at onset of symptoms is in the 30s (PARK4) or 40s (PARK1). Progression appears to be faster than in sporadic PD and dementia is a frequent finding; at times the clinical picture resembles DLB, but mean age at onset is much lower than in sporadic cases (Polymeropoulos et al. 1997; Spira et al. 2001; Zarranz et al. 2004). PARK1 and PARK4 are attributable to SNCA mutations and duplications/triplications, respectively.

b. PARK3 (gene unknown): Researchers described a group of families with parkinsonism closely resembling that of sporadic $\mathrm{PD}$, including age of onset (mean $59 \mathrm{yr}$ ); the locus has been mapped to $2 \mathrm{p} 13$. Penetrance was estimated to be below $40 \%$ (Gasser et al. 1998). It has not been clearly defined whether this represents a disease susceptibility locus or a true Mendelian form of PD.

c. PARK5 (gene UCHL1, ubiquitin carboxyterminal hydrolase 1): Only one family has been reported with $\mathrm{PD}$ and a mutation in UCHL1, providing frail evidence that this is 
Clinical Approach to Parkinson's Disease

Table 4. Causes of parkinsonism

\section{Heredodegenerative}

Dementia with Lewy bodies, multiple system atrophy, progressive supranuclear palsy, corticobasal syndrome, fragile X-tremor ataxia syndrome, neurodegeneration with brain iron accumulation (includes pantothenate kinase-associated neurodegeneration, PLA2G6-associated neurodegeneration or PARK 14, neuroferritinopathy, aceruloplasminemia, and $F A 2 H$-associated neurodegeneration), pallido-pyramidal syndromes (includes Kufor-Rakeb disease or PARK9, and neurodegeneration associated with FBXO7 mutations or PARK 15), Perry syndrome (DCTN1 mutations), X-linked dystonia parkinsonism (DYT3, Lubag), doparesponsive dystonia (DYT5), rapid-onset dystonia parkinsonism (DYT12), autosomal recessive dystonia parkinsonism (DYT16), dopamine transporter deficiency syndrome (mutations in SLC6A3), SENDA syndrome, Huntington's disease, Huntington disease-like type 2, chorea-acanthocytosis, MacLeod syndrome, some spinocerebellar ataxias (SCA3, SCA6, SCA8, SCA13, and SCA17), dentato-rubro-pallidoluysian atrophy, hereditary spastic paraparesis types 11 (SPG11) and 15 (SPG15), frontotemporal dementia with parkinsonism (FTDP-17), prion disease (Creutzfeldt-Jakob, Gertsmann-Sträussler-Scheinker), parkinsonism-dementia-ALS complex of Guam (Lytico-Bodig), Fahr's disease, intraneuronal cytoplasmic inclusion disease, and neurofilament inclusion body disease

\section{Structural brain lesions}

Cerebrovascular disease, infectious brain lesions (e.g., cryptococcosis, neurosyphilis), postencephalitic (e.g., encephalitis lethargica), postanoxic injury, posttraumatic (e.g., dementia pugilistica), toxic (e.g., MPTP, ephedrone, manganese, carbon monoxide, cyanide), metabolic disorders (Wilson, Niemann-Pick Type C, Gaucher, GM1 gangliosidosis, phenylketonuria, cerebrotendinous xanthomatosis, maple syrup urine disease, mitochondrial disorders with striatal necrosis, ceroid neuronal lipofuscinosis), secondary Fahr's syndrome, nonWilsonian acquired hepatocerebral degeneration, hemiparkinsonism-hemiatrophy syndrome, hydrocephalus, and intracranial tumors

\section{Drug-induced}

Typical antipsychotics (e.g., haloperidol, chlorpromazine), most atypical antipsychotics (riperidone, olanzapine), tetrabenazine, reserpine, methyldopa, metoclopramide, flunarizine, cinnarizine, verapamil, valproic acid, lithium, and others

\section{Psychogenic (functional)}

Table compiled with data from Schrag and Schott 2006; Wijemanne and Jankovic 2007; Alvarez and Evidente 2008; Edwards et al. 2008c; Farrer et al. 2009; Klein et al. 2009; Schneider et al. 2009; Kruer et al. 2010; Schneider and Bhatia 2010; Carecchio et al. 2011; Kurian et al. 2011.

Most disorders in the first group are degenerative.

Abbreviations: ALS, amyotrophic lateral sclerosis; MPTP, 1-methyl-4-phenyl-1,2,3,6-tetrahydropyridine.

a true locus for inherited PD. The clinical picture resembles that of sporadic $\mathrm{PD}$, with age at onset of symptoms around 50 years of age (Leroy et al. 1998).

d. PARK8 (gene LRRK2, leucine-rich repeat kinase 2 or dardarin): Probably the most common type of inherited PD. The clinical picture resembles that of late-onset sporadic $\mathrm{PD}$; abduction-adduction lower limb tremor could be a useful diagnostic hint (Wszolek et al. 2004; Healy et al. 2008). Mutation frequency may be as high as 40\% in North African Arabs and Ashkenazi Jewish populations; countries from southern Europe also have high mutation frequency (Healyet al. 2008). There is considerable neuropathological heterogeneity in these patients (Wszolek et al. 2004).

2. Autosomal recessive (AR) PD:

a. PARK2 (gene Parkin): This is by far the most common disorder in the group of the AR and one of the most common forms of monogenic PD. Age at onset of symptoms ranges from childhood to mid-50s. It accounts for most PD cases under the age of $30 \mathrm{yr}$. Typical clinical features include early prominent dystonia (especially foot dystonia), exquisite response to levodopa 
and anticholinergic drugs, slow disease progression, diurnal fluctuations, sleep benefit, susceptibility to levodopa-induced peak-dose dyskinesias, and wearing-off phenomenon. Hyperreflexia is a common feature. Other possible presentations include exercise-induced dystonia, focal dystonia, tremor-predominant cases, and early impairment of gait and balance (Abbas et al. 1999; Klein et al. 2000; Lücking et al. 2000; Gouider-Khouja et al. 2003; Kahn et al. 2003; Wickremaratchi et al. 2009). Nonmotor symptoms seem to be less prevalent than in sporadic PD, except anxiety (Kägi et al. 2010b). Lewy bodies were absent in most patients that came to autopsy (Farrer et al. 2001; Gouider-Khouja et al. 2003).

b. PARK6 (gene PINK1, PTEN-induced putative kinase 1): It is characterized by early onset in most patients (mean age at onset in the 30s, ranging from childhood until the seventh decade of life), dystonia at onset or symptom symmetry in some cases, slow disease progression, excellent levodopa responsiveness, early peak-dose dyskinesias; hyperreflexia has been described; rare cases with very early onset display sleep benefit and diurnal fluctuations (Valente et al. 2001, 2002; Bonifati 2005; Ibáñez et al. 2006; Leutenegger et al. 2006). Psychiatric disturbances such as depression, anxiety, and psychosis are a frequent finding (Bonifati 2005; Ibáñez et al. 2006; Steinlechner et al. 2007). Lewy bodies are a recently described neuropathological finding (Samaranch et al. 2010).

c. PARK7 (gene DJ-1): This seems to be a rare disorder, with a clinical phenotype similar to PARK6. Notably, some cases have been associated with blepharospasm, whereas amyotrophic lateral sclerosis and dementia have been described in one family (van Duijn et al. 2001; AbouSleiman et al. 2003; Dekker et al. 2003; Clark et al. 2009; Annesi et al. 2005).

Other candidate genes have been associated with parkinsonism, namely, Nurr1 (Le et al. 2003), synphylin-1 (Marx et al. 2003), and POLG (polymerase gamma) (Davidzon et al. 2006), but further confirmation in large case series is still awaited. Exciting observations have been made in the last few years in families with members suffering from Gaucher's disease (GD), an AR disorder caused by homozygous mutations in the GBA gene encoding the lysosomal enzyme glucocerebrosidase. Heterozygous carriers, who do not have GD, are at higher risk of developing sporadic PD or DLB (Aharon-Peretz et al. 2004; Clark et al. 2009; Sidransky et al. 2009). Thus, interest emerged in the putative role of ceramide in the pathogenesis of Lewy body disorders (Bras et al. 2008).

\section{PD MANAGEMENT: BRIEF CONSIDERATIONS}

Comprehensive review of PD therapy is beyond the scope of this text, but a few basic thoughts must be set forth. PD is best managed in a multidisciplinary setting, to obtain satisfactory results regarding the various disabling aspects of the disease. Nonmotor symptoms should be treated accordingly, although evidence to support most treatment decisions is scarce; sildenafil should be considered for erectile dysfunction and macrogol for constipation (Zesiewicz et al. 2010). Dementia symptoms are improved by cholinesterase inhibitors or memantine (Emre et al. 2010; van Laar et al. 2011). An array of drugs is used to treat motor symptoms in PD (availability varies from country to country): levodopa plus peripheral dopa decarboxylase inhibitor (carbidopa or benserazide), dopamine agonists (ergot derivatives: bromocriptine, pergolide, cabergoline, dihydroergocryptine; non-ergot derivatives: ropinirole, pramipexole, rotigotine, apomorphine), monoamine oxidase $\mathrm{B}$ inhibitors (selegiline, rasagiline), catechol-O-methyltransferase inhibitors (entacapone, tolcapone), anticholinergics (trihexyphenidyl, benztropine), and amantadine. Currently, there is no consensus on the most adequate timing and drug of choice for therapy initiation in $\mathrm{PD}$, but dopaminergic therapy is usually deferred until deteriorating quality of life demands treatment, owing to the future potential motor complications brought 
about by these drugs, such as peak-dose dyskinesias (see online Movie 9 at www.perspectivesinmedicine.org), wearing off, and sudden off states (Edwards et al. 2008a; Lang 2009). Levodopa seems to pose higher risks in this regard as compared with dopamine agonists, although recent data brought conflicting views on this matter (Katzenschlager et al. 2008; Holloway et al. 2009). Nevertheless, levodopa is the most effective drug in the control of motor symptoms, and PD patients typically show marked and sustained benefits from it for several years (Schapira et al. 2009). Dopamine agonists may cause peripheral edema, fibrotic reactions (most ergot derivatives), excessive daytime somnolence, and impulse control disorders (Antonini et al. 2009). In advanced PD, functional neurosurgery is a valuable therapeutic option, provided that patients are carefully selected (Lang et al. 2006). Deep brain stimulation of either the subthalamic nucleus or internal globus pallidus is an effective and generally safe procedure (Deuschl et al. 2006; Follett et al. 2010; Moro et al. 2010). In advanced PD it may be more effective for the control of motor symptoms than the best medical therapy, either alone or in combination with it (Weaver et al. 2009; Williams et al. 2010).

\section{CONCLUDING REMARKS}

$\mathrm{PD}$ is a common and potentially disabling disorder. Suitable efforts should be performed to achieve accurate diagnosis, communicate a plausible prognosis to the patient and family, and proceed with the best therapeutic interventions. Remarkable progress has been made in the last two decades in the field of genetics, pathophysiology, and clinical imaging, but the diagnosis of PD still sits inevitably on clinical skills and exploration, which emphasizes the importance of a solid clinical knowledge about the disease.

\section{ACKNOWLEDGMENTS}

We thank the patients who generously contribute every day by willingly consenting to video capture and educational display.

\section{REFERENCES}

* Reference is also in this collection.

Abbas N, Lücking CB, Ricard S, Dürr A, Bonifati V, De Michele G, Bouley S, Vaughan JR, Gasser T, Marconi R, et al. 1999. A wide variety of mutations in the parkin gene are responsible for autosomal recessive parkinsonism in Europe. French Parkinson's Disease Genetics Study Group and the European Consortium on Genetic Susceptibility in Parkinson's Disease. Hum Mol Genet 8: 567-574.

Abou-Sleiman PM, Healy DG, Quinn N, Lees AJ, Wood NW. 2003. The role of pathogenic DJ-1 mutations in Parkinson's disease. Ann Neurol 54: 283-286.

Aharon-Peretz J, Rosenbaum H, Gershoni-Baruch R. 2004. Mutations in the glucocerebrosidase gene and Parkinson's disease in Ashkenazi Jews. $N$ Engl J Med 351: $1972-1977$.

Alvarez MVG, Evidente VGH. 2008. Understanding druginduced parkinsonism: Separating pearls from oysters. Neurology 70: 32-34.

Alves G, Forsaa EB, Pedersen KF, Gjerstad MD, Larsen JP. 2008. Epidemiology of Parkinson's disease. J Neurol 255: S18-S32.

Annesi G, Savettieri G, Pugliese P, D’Amelio M, Tarantino P, Ragonese P, La Bella V, Piccoli T, Civitelli D, Annesi F, et al. 2005. DJ-1 mutations and parkinsonism-dementiaamyotrophic lateral sclerosis complex. Ann Neurol 58: 803-807.

Antonini A, Tolosa E, Mizuno Y, Yamamoto M, Poewe WH. 2009. A reassessment of risks and benefits of dopamine agonists in Parkinson's disease. Lancet Neurol 8: 929937.

Bain P. 2007. Tremor. Parkinsonism Relat Disord 13: S369S374.

Bain PG, Findley LJ, Thompson PD, Gresty MA, Rothwell JC, Harding AE, Marsden CD. 1994. A study of hereditary essential tremor. Brain 117: 805-824.

Berry-Kravis E, Abrams L, Coffey SM, Hall DA, Greco C, Gane LW, Grigsby J, Bourgeois JA, Finucane B, Jacquemont S, et al. 2007. Fragile X-associated tremor/ataxia syndrome: Clinical features, genetics, and testing guidelines. Mov Disord 22: 2018-2030.

Bonifati V, Rohé CF, Breedveld GJ, Fabrizio E, De Mari M, Tassorelli C, Tavella A, Marconi R, Nicholl DJ, Chien HF, et al. 2005. Early-onset parkinsonism associated with PINK1 mutations: Frequency, genotypes, and phenotypes. Neurology 65: 87-95.

Braak H, Del Tredici K, Rüb U, de Vos RA, Jansen Steur EN, Braak E. 2003. Staging of brain pathology related to sporadic Parkinson's disease. Neurobiol Aging 24: 197211.

Bras J, Singleton A, Cookson MR, Hardy J. 2008. Emerging pathways in genetic Parkinson's disease: Potential role of ceramide metabolism in Lewy body disease. FEBS J 275: 5767-5773.

Bronstein J, Carvey P, Chen H, Cory-Slechta D, DiMonte D, Duda J, English P, Goldman S, Grate S, Hansen J, et al. 2009. Meeting report: Consensus statement-Parkinson's disease and the environment: Collaborative on health and the environment and Parkinson's Action 
J. Massano and K.P. Bhatia

Network (CHE PAN) conference, 26-28 June 2007. Environ Health Perspect 117: 117-121.

Carecchio M, Schneider SA, Chan H, Lachmann R, Lee PJ, Murphy E, Bhatia KP. 2011. Movement disorders in adult surviving patients with maple syrup urine disease. Mov Disord 26: 1324-1328.

Castelo-Branco M, Mendes M, Silva F, Massano J, Januário G, Januário C, Freire A. 2009. Motion integration deficits are independent of magnocellular impairment in Parkinson's disease. Neuropsychologia 47: 314-320.

Chaudhuri KR, Schapira AH. 2009. Non-motor symptoms of Parkinson's disease: Dopaminergic pathophysiology and treatment. Lancet Neurol 8: 464-474.

Clark LN, Kartsaklis LA, Wolf Gilbert R, Dorado B, Ross BM, Kisselev S, Verbitsky M, Mejia-Santana H, Cote LJ, Andrews H, et al. 2009. Association of glucocerebrosidase mutations with dementia with Lewy bodies. Arch Neurol 66: $578-583$.

Davidzon G, Greene P, Mancuso M, Klos KJ, Ahlskog JE, Hirano M, DiMauro S. 2006. Early-onset familial parkinsonism due to POLG mutations. Ann Neurol 59: 859862.

Dekker M, Bonifati V, van Swieten J, Leenders N, Galjaard RJ, Snijders P, Horstink M, Heutink P, Oostra B, van Duijn C. 2003. Clinical features and neuroimaging of PARK7-linked parkinsonism. Mov Disord 18: 751-757.

De Lau LML, Breteler MMB. 2006. Epidemiology of Parkinson's disease. Lancet Neurol 5: 525-535.

Deuschl G, Bain P, Brin M. 1998. Consensus statement of the Movement Disorder Society on Tremor. Ad Hoc Scientific Committee. Mov Disord 13: S2-S23.

Deuschl G, Schade-Brittinger C, Krack P, Volkmann J, Schäfer H, Bötzel K, Daniels C, Deutschländer A, Dillmann U, Eisner W, et al. 2006. A randomized trial of deep-brain stimulation for Parkinson's disease. N Engl J Med 355: 896-908.

Dorsey ER, Constantinescu R, Thompson JP, Biglan KM, Holloway RG, Kieburtz K, Marshall FJ, Ravina BM, Schifitto G, Siderowf A, et al. 2007. Projected number of people with Parkinson disease in the most populous nations, 2005 through 2030. Neurology 68: 384-386.

Edwards M, Quinn N, Bhatia K. 2008a. Parkinson's disease. In Parkinson's disease and other movement disorders, pp. 17-80. Oxford University Press, Oxford.

Edwards M, Quinn N, Bhatia K. 2008b. Tremor. In Parkinson's disease and other movement disorders, pp. 102-118. Oxford University Press, Oxford.

Edwards M, Quinn N, Bhatia K. 2008c. Atypical parkinsonism. In Parkinson's disease and other movement disorders, pp. 81-100. Oxford University Press, Oxford.

Elbaz A, Moisan F. 2008. Update in the epidemiology of Parkinson's disease. Curr Opin Neurol 21: 454-460.

Emre M, Aarsland D, Brown R, Burn DJ, Duyckaerts C, Mizuno Y, Broe GA, Cummings J, Dickson DW, Gauthier S, et al. 2007. Clinical diagnostic criteria for dementia associated with Parkinson's disease. Mov Disord 22: 1689-1707.

Emre M, Tsolaki M, Bonuccelli U, Destée A, Tolosa E, Kutzelnigg A, Ceballos-Baumann A, Zdravkovic S, Bladström A, Jones R, et al. 2010. Memantine for patients with Parkinson's disease dementia or dementia with
Lewy bodies: A randomised, double-blind, placebo-controlled trial. Lancet Neurol 9: 969-977.

Farrer M, Chan P, Chen R, Tan L, Lincoln S, Hernandez D, Forno L, Gwinn-Hardy K, Petrucelli L, Hussey J, et al. 2001. Lewy bodies and parkinsonism in families with parkin mutations. Ann Neurol 50: 293-300.

Farrer MJ, Hulihan MM, Kachergus JM, Dächsel JC, Stoessl AJ, Grantier LL, Calne S, Calne DB, Lechevalier B, Chapon F, et al. 2009. DCTN1 mutations in Perry syndrome. Nat Genet 41: 163-165.

Follett KA, Weaver FM, Stern M, Hur K, Harris CL, Luo P, Marks WJ Jr, Rothlind J, Sagher O, Moy C, et al. 2010. Pallidal versus subthalamic deep-brain stimulation for Parkinson's disease. N Engl J Med 362: 2077-2091.

Gallagher DA, Lees AJ, Schrag A. 2010. What are the most important nonmotor symptoms in patients with Parkinson's disease and are we missing them? Mov Disord 25: 2493-2500.

Gasser T. 2007. Update on the genetics of Parkinson's disease. Mov Disord 22: S343-S350.

Gasser T, Müller-Myhsok B, Wszolek ZK, Oehlmann R, Calne DB, Bonifati V, Bereznai B, Fabrizio E, Vieregge P, Horstmann RD. 1998. A susceptibility locus for Parkinson's disease maps to chromosome 2p13. Nat Genet 18: $262-265$.

Gao X, Chen H, Schwarzschild MA, Ascherio A. 2011. Use of ibuprofen and risk of Parkinson disease. Neurology 76: $863-869$.

Geser F, Wenning GK, Poewe W, McKeith I. 2005. How to diagnose dementia with Lewy bodies: State of the art. Mov Disord 20 (Suppl 12): S11-S20.

Gilman S, Wenning GK, Low PA, Brooks DJ, Mathias CJ, Trojanowski JQ, Wood NW, Colosimo C, Dürr A, Fowler CJ, et al. 2008. Second consensus statement on the diagnosis of multiple system atrophy. Neurology 71: 670-676.

* Goetz CG. 2011. The history of Parkinson's disease: Early clinical descriptions and neurological therapies. Cold Spring Harb Perspect Med doi: 10.1101/cshperspect. a008862.

Goetz CG, Poewe W, Rascol O, Sampaio C, Stebbins GT, Counsell C, Giladi N, Holloway RG, Moore CG,Wenning GK, et al. 2004. Movement Disorder Society Task Force report on the Hoehn and Yahr staging scale: Status and recommendations. Mov Disord 19: 1020-1028.

Gouider-Khouja N, Larnaout A, Amouri R, Sfar S, Belal S, Ben Hamida C, Ben Hamida M, Hattori N, Mizuno Y, Hentati F. 2003. Autosomal recessive parkinsonism linked to parkin gene in a Tunisian family. Clinical, genetic and pathological study. Parkinsonism Relat Disord 9: $247-251$.

Hawkes CH, Del Tredici K, Braak H. 2010. A timeline for Parkinson's disease. Parkinsonism Relat Disord 16: 79-84.

Healy DG, Falchi M, O'Sullivan SS, Bonifati V, Durr A, Bressman S, Brice A, Aasly J, Zabetian CP, Goldwurm S, et al. 2008. Phenotype, genotype, and worldwide genetic penetrance of LRRK2-associated Parkinson's disease: A case-control study. Lancet Neurol 7: 583-590.

Hirtz D, Thurman DJ, Gwinn-Hardy K, Mohamed M, Chaudhuri AR, Zalutsky R. 2007. How common are the "common" neurologic disorders? Neurology 68: 326337. 
Holloway R, Marek K, Biglan K, Dick A, Fahn S, JulianBaros E, Kamp C, Kieburtz K, Lang A, McDermott M, et al. 2009. Long-term effect of initiating pramipexole vs levodopa in early Parkinson disease. Arch Neurol 66: 563-570.

Hughes AJ, Daniel SE, Kilford L, Lees AJ. 1992. Accuracy of clinical diagnosis of idiopathic Parkinson's disease: A clinico-pathological study of 100 cases. J Neurol Neurosurg Psychiatry 55: 181-184.

Ibáñez P, Lesage S, Lohmann E, Thobois S, De Michele G, Borg M, Agid Y, Dürr A, Brice A, French Parkinson's Disease Genetics Study Group. 2006. Mutational analysis of the PINK1 gene in early-onset parkinsonism in Europe and North Africa. Brain 129: 686-694.

Jacquemont S, Hagerman RJ, Hagerman PJ, Leehey MA. 2007. Fragile-X syndrome and fragile $X$-associated tremor/ataxia syndrome: Two faces of FMR1. Lancet Neurol 6: $45-55$.

Jain S, Lo SE, Louis ED. 2006. Common misdiagnosis of a common neurological disorder: How are we misdiagnosing essential tremor? Arch Neurol 63: 1100-1104.

Jankovic J, 2008. Parkinson's disease: Clinical features and diagnosis. J Neurol Neurosurg Psychiatry 79: 368-376.

Kägi G, Bhatia KP, Tolosa E. 2010a. The role of DAT-SPECT in movement disorders. J Neurol Neurosurg Psychiatry 81: $5-12$.

Kägi G, Klein C, Wood NW, Schneider SA, Pramstaller PP, Tadic V, Quinn NP, van de Warrenburg BP, Bhatia KP. 2010b. Nonmotor symptoms in Parkin gene-related parkinsonism. Mov Disord 25: 1279-1284.

Kalra S, Grosset DG, Benamer HTS. 2010. Differentiating vascular parkinsonism from idiopathic Parkinson's disease: A systematic review. Mov Disord 25: 149-156.

Katzenschlager R, Head J, Schrag A, Ben-Shlomo Y, Evans A, Lees AJ, Parkinson's Disease Research Group of the United Kingdom. 2008. Fourteen-year final report of the randomized PDRG-UK trial comparing three initial treatments in PD. Neurology 71: 474-480.

Khan NL, Graham E, Critchley P, Schrag AE, Wood NW, Lees AJ, Bhatia KP, Quinn N. 2003. Parkin disease: A phenotypic study of a large case series. Brain 126: 1279-1292.

* Klein C, Westenberger A. 2012. Genetics of Parkinson's disease. Cold Spring Harb Perspect Med 2: a008888.

Klein C, Pramstaller PP, Kis B, Page CC, Kann M, Leung J, Woodward H, Castellan CC, Scherer M, Vieregge P, et al. 2000. Parkin deletions in a family with adult-onset, tremor-dominant parkinsonism: Expanding the phenotype. Ann Neurol 48: 65-71.

Klein C, Schneider SA, Lang AE. 2009. Hereditary parkinsonism: Parkinson disease look-alikes-An algorithm for clinicians to "PARK" genes and beyond. Mov Disord 24: 2042-2058.

Kruer MC, Paisán-Ruiz C, Boddaert N, Yoon MY, Hama H, Gregory A, Malandrini A, Woltjer RL, Munnich A, Gobin S, et al. 2010. Defective FA2H leads to a novel form of neurodegeneration with brain iron accumulation (NBIA). Ann Neurol 68: 611-618.

Kurian MA, Li Y, Zhen J, Meyer E, Hai N, Christen HJ, Hoffmann GF, Jardine P, von Moers A, Mordekar SR, et al. 2011. Clinical and molecular characterisation of hereditary dopamine transporter deficiency syndrome:
An observational cohort and experimental study. Lancet Neurol 10: 54-62.

Lang AE. 2009. When and how should treatment be started in Parkinson disease? Neurology 72: S39-S43.

Lang AE, Houeto JL, Krack P, Kubu C, Lyons KE, Moro E, Ondo W, Pahwa R, Poewe W, Tröster AI, et al. 2006. Deep brain stimulation: Preoperative issues. Mov Disord 21: S171-S196.

Lanska DJ. 2010. The history of movement disorders. In History of clinical neurology: Handbook of clinical neurology (ed. Finger S, Boller F, Tyler KL), Vol. 95, pp. 501546. Elsevier, Amsterdam.

Le WD, Xu P, Jankovic J, Jiang H, Appel SH, Smith RG, Vassilatis DK. 2003. Mutations in NR4A2 associated with familial Parkinson disease. Nat Genet 33: 85-89.

Lees AJ. 2007. Unresolved issues relating to the shaking palsy on the celebration of James Parkinson's 250th birthday. Mov Disord 22: S327-S334.

Lees AJ, Hardy J, Revesz T. 2009. Parkinson's disease. Lancet 373: 2055-2066.

Leroy E, Boyer R, Auburger G, Leube B, Ulm G, Mezey E, Harta G, Brownstein MJ, Jonnalagada S, Chernova T, et al. 1998. The ubiquitin pathway in Parkinson's disease. Nature 395: 451-452.

Leutenegger AL, Salih MA, Ibáñez P, Mukhtar MM, Lesage S, Arabi A, Lohmann E, Dürr A, Ahmed AE, Brice A. 2006. Juvenile-onset Parkinsonism as a result of the first mutation in the adenosine triphosphate orientation domain of PINK1. Arch Neurol 63: 1257-1261.

Lim SY, Fox SH, Lang AE. 2009. Overview of the extranigral aspects of Parkinson disease. Arch Neurol 66: 167-172.

Litvan I, Bhatia KP, Burn DJ, Goetz CG, Lang AE, McKeith I, Quinn N, Sethi KD, Shults C, Wenning GK, et al. 2003. Movement Disorders Society Scientific Issues Committee report: SIC Task Force appraisal of clinical diagnostic criteria for Parkinsonian disorders. Mov Disord 18: 467-486.

Lücking CB, Dürr A, Bonifati V, Vaughan J, De Michele G, Gasser T, Harhangi BS, Meco G, Denèfle P, Wood NW, et al. 2000. Association between early-onset Parkinson's disease and mutations in the parkin gene. $N$ Engl J Med 342: $1560-1567$.

Massano J, Costa F, Nadais G. 2008. Teaching neuroImage: MRI in multiple system atrophy: "Hot cross bun" sign and hyperintense rim bordering the putamina. Neurology 71: e38.

Marsden CD. 1982. The mysterious motor function of the basal ganglia: The Robert Wartenberg Lecture. Neurology 32: $514-539$.

Marsden CD. 1994. Parkinson's disease. J Neurol Neurosurg Psychiatry 57: 672-681.

Marx FP, Holzmann C, Strauss KM, Li L, Eberhardt O, Gerhardt E, Cookson MR, Hernandez D, Farrer MJ, Kachergus J, et al. 2003. Identification and functional characterization of a novel R621C mutation in the synphilin-1 gene in Parkinson's disease. Hum Mol Genet 12: $1223-1231$.

Moro E, Lozano AM, Pollak P, Agid Y, Rehncrona S, Volkmann J, Kulisevsky J, Obeso JA, Albanese A, Hariz MI, et al. 2010. Long-term results of a multicenter study on 
J. Massano and K.P. Bhatia

subthalamic and pallidal stimulation in Parkinson's disease. Mov Disord 25: 578-586.

* Niethammer M, Feigin A, Eidelberg D. 2012. Functional neuroimaging in Parkinson's disease. Cold Spring Harb Perspect Med doi: 10.1101/cshperspect.a009274.

Parkinson J. 1817. An essay on the shaking palsy. Sherwood, Neely, and Jones, London.

Parkinson J. 2002. An essay on the shaking palsy. 1817. J Neuropsychiatry Clin Neurosci 14: 223-236.

Plotnik M, Giladi N, Dagan Y, Hausdorff JM. 2011. Postural instability and fall risk in Parkinson's disease: Impaired dual tasking, pacing, and bilateral coordination of gait during the "ON" medication state. Exp Brain Res 210: $529-538$.

Poewe W. 2008. Non-motor symptoms in Parkinson's disease. Eur J Neurol 15: S14-S20.

Polymeropoulos MH, Lavedan C, Leroy E, Ide SE, Dehejia A, Dutra A, Pike B, Root H, Rubenstein J, Boyer R, et al. 1997. Mutation in the $\alpha$-synuclein gene identified in families with Parkinson's disease. Science 276: 2045 2047.

Quinn NP, Schneider SA, Schwingenschuh P, Bhatia KP. 2011. Tremor-Some controversial aspects. Mov Disord 16: $18-23$.

Rodríguez-Oroz MC, Jahanshahi M, Krack P, Litvan I, Macias R, Bezard E, Obeso JA. 2009. Initial clinical manifestations of Parkinson's disease: Features and pathophysiological mechanisms. Lancet Neurol 8: 1128-1139.

Samaranch L, Lorenzo-Betancor O, Arbelo JM, Ferrer I, Lorenzo E, Irigoyen J, Pastor MA, Marrero C, Isla C, Herrera-Henriquez J, et al. 2010. PINK1-linked parkinsonism is associated with Lewy body pathology. Brain 133: $1128-1142$.

Savica R, Rocca WA, Ahlskog JE. 2010. When does Parkinson disease start? Arch Neurol 67: 798-801.

Schapira AH, Emre M, Jenner P, Poewe W. 2009. Levodopa in the treatment of Parkinson's disease. Eur J Neurol 16: 982-986.

Schapira AH, Tolosa E. 2010. Molecular and clinical prodrome of Parkinson disease: Implications for treatment. Nat Rev Neurol 6: 309-317.

Schlesinger I, Schlesinger N. 2008. Uric acid in Parkinson's disease. Mov Disord 23: 1653-1657.

Schneider SA, Bhatia KP. 2010. Rare causes of dystonia parkinsonism. Curr Neurol Neurosci Rep 10: 431-439.

Schneider SA, Edwards MJ, Mir P, Cordivari C, Hooker J, Dickson J, Quinn N, Bhatia KP. 2007. Patients with adultonset dystonic tremor resembling parkinsonian tremor have scans without evidence of dopaminergic deficit (SWEDDs). Mov Disord 22: 2210-2215.

Schneider SA, Bhatia KP, Hardy J. 2009. Complicated recessive dystonia parkinsonism syndromes. Mov Disord 24: 490-499.

Schrag A, Schott JM. 2006. Epidemiological, clinical, and genetic characteristics of early-onset parkinsonism. Lancet Neurol 5: 355-363.

Schrag A, Münchau A, Bhatia KP, Quinn NP, Marsden CD. 2000. Essential tremor: An overdiagnosed condition? J Neurol 247: 955-959.
Schwingenschuh P, Ruge D, Edwards MJ, Terranova C, Katschnig P, Carrillo F, Silveira-Moriyama L, Schneider SA, Kägi G, Palomar FJ, et al. 2010. Distinguishing SWEDDs patients with asymmetric resting tremor from Parkinson's disease: A clinical and electrophysiological study. Mov Disord 25: 560-569.

Sethi K. 2008. Levodopa unresponsive symptoms in Parkinson disease. Mov Disord 23: S521-S533.

Sidransky E, Nalls MA, Aasly JO, Aharon-Peretz J, Annesi G, Barbosa ER, Bar-Shira A, Berg D, Bras J, Brice A, et al. 2009. Multicenter analysis of glucocerebrosidase mutations in Parkinson's disease. N Engl J Med 361: 16511661.

Silva MF, Faria P, Regateiro FS, Forjaz V, Januário C, Freire A, Castelo-Branco M. 2005. Independent patterns of damage within magno-, parvo- and koniocellular pathways in Parkinson's disease. Brain 128: 2260-2271.

Sitburana O, Ondo WG. 2009. Brain magnetic resonance imaging (MRI) in parkinsonian disorders. Parkinsonism Relat Disord 15: 165-174.

Spildooren J, Vercruysse S, Desloovere K, Vandenberghe W, Kerckhofs E, Nieuwboer A. 2010. Freezing of gait in Parkinson's disease: The impact of dual-tasking and turning. Mov Disord 25: 2563-2570.

Spira PJ, Sharpe DM, Halliday G, Cavanagh J, Nicholson GA. 2001. Clinical and pathological features of a Parkinsonian syndrome in a family with an Ala53Thr $\alpha$-synuclein mutation. Ann Neurol 49: 313-319.

Stefanova N, Bücke P, Duerr S, Wenning GK. 2009. Multiple system atrophy: An update. Lancet Neurol 8: 1172-1178.

Steinlechner S, Stahlberg J, Völkel B, Djarmati A, Hagenah J, Hiller A, Hedrich K, König I, Klein C, Lencer R. 2007. Cooccurrence of affective and schizophrenia spectrum disorders with PINK1 mutations. J Neurol Neurosurg Psychiatry 78: $532-535$.

Tolosa E, Wenning G, Poewe W. 2006. The diagnosis of Parkinson's disease. Lancet Neurol 5: 75-86.

Tolosa E, Gaig C, Santamaría J, Compta Y. 2009. Diagnosis and the premotor phase of Parkinson disease. Neurology 27: $\mathrm{S} 12-\mathrm{S} 20$.

Twelves D, Perkins KS, Counsell C. 2003. Systematic review of incidence studies of Parkinson's disease. Mov Disord 18: $19-31$.

Valente EM, Bentivoglio AR, Dixon PH, Ferraris A, Ialongo T, Frontali M, Albanese A, Wood NW. 2001. Localization of a novel locus for autosomal recessive early-onset parkinsonism, PARK6, on human chromosome 1p35-p36. Am J Hum Genet 68: 895-900.

Valente EM, Brancati F, Ferraris A, Graham EA, Davis MB, Breteler MM, Gasser T, Bonifati V, Bentivoglio AR, De Michele G, et al. 2002. PARK6-linked parkinsonism occurs in several European families. Ann Neurol 51: 14-18.

Valente EM, Abou-Sleiman PM, Caputo V, Muqit MM, Harvey K, Gispert S, Ali Z, Del Turco D, Bentivoglio AR, Healy DG, et al. 2004. Hereditary early-onset Parkinson's disease caused by mutations in PINK1. Science 304: $1158-1160$.

van Duijn CM, Dekker MC, Bonifati V, Galjaard RJ, Houwing-Duistermaat JJ, Snijders PJ, Testers L, Breedveld GJ, Horstink M, Sandkuijl LA, et al. 2001. Park7, a 
Clinical Approach to Parkinson's Disease

novel locus for autosomal recessive early-onset parkinsonism, on chromosome 1p36. Am J Hum Genet 69: 629-634.

van Laar T, De Deyn PP, Aarsland D, Barone P, Galvin JE. 2011. Effects of cholinesterase inhibitors in Parkinson's disease dementia: A review of clinical data. CNS Neurosci Ther 17: 428-441.

Von Campenhausen S, Bornschein B, Wick R, Bötzel K, Sampaio C, Poewe W, Oertel W, Sibert U, Berger K, Dodel R. 2005. Prevalence and incidence of Parkinson's disease in Europe. Eur Neuropsychopharmacol 15: 473-490.

Warren NM, Burn DJ. 2007. Progressive supranuclear palsy. Pract Neurol 7: 16-23.

Weaver FM, Follett K, Stern M, Hur K, Harris C, Marks WJ Jr, Rothlind J, Sagher O, Reda D, Moy CS, et al. 2009. Bilateral deep brain stimulation vs best medical therapy for patients with advanced Parkinson disease: A randomized controlled trial. JAMA 301: 63-73.

Weisman D, McKeith I. 2007. Dementia with Lewy bodies. Semin Neurol 27: 42-47.

Wickremaratchi MM, Majounie E, Morris HR, Williams NM, Lewis H, Gill SS, Khan S, Heywood P, Hardy J, Wiles CM, et al. 2009. Parkin-related disease clinically diagnosed as a pallido-pyramidal syndrome. Mov Disord 24: $138-140$.

Wijemanne S, Jankovic J. 2007. Hemiparkinsonism-hemiatrophy syndrome. Neurology 69: 1585-1594.

Williams DR, Lees AJ. 2009. Progressive supranuclear palsy: Clinicopathological concepts and diagnostic challenges. Lancet Neurol 8: 270-279.
Williams DR, de Silva R, Paviour DC, Pittman A, Watt HC, Kilford L, Holton JL, Revesz T, Lees AJ. 2005. Characteristics of two distinct clinical phenotypes in pathologically proven progressive supranuclear palsy: Richardson's syndrome and PSP-parkinsonism. Brain 128: 1247-1258.

Williams A, Gill S, Varma T, Jenkinson C, Quinn N, Mitchell R, Scott R, Ives N, Rick C, Daniels J, et al. 2010. Deep brain stimulation plus best medical therapy versus best medical therapy alone for advanced Parkinson's disease (PD SURG trial): A randomised, open-label trial. Lancet Neurol 9: 581-591.

Winikates J, Jankovic J. 1999. Clinical correlates of vascular parkinsonism. Arch Neurol 56: 98-102.

Wszolek ZK, Pfeiffer RF, Tsuboi Y, Uitti RJ, McComb RD, Stoessl AJ, Strongosky AJ, Zimprich A, Müller-Myhsok B, Farrer MJ, et al. 2004. Autosomal dominant parkinsonism associated with variable synuclein and tau pathology. Neurology 62: 1619-1622.

Zarranz JJ, Alegre J, Gómez-Esteban JC, Lezcano E, Ros R, Ampuero I, Vidal L, Hoenicka J, Rodriguez O, Atarés B, et al. 2004. The new mutation, E46K, of $\alpha$-synuclein causes Parkinson and Lewy body dementia. Ann Neurol 55: $164-173$.

Zesiewicz TA, Sullivan KL, Arnulf I, Chaudhuri KR, Morgan JC, Gronseth GS, Miyasaki J, Iverson DJ, Weiner WJ, Quality Standards Subcommittee of the American Academy of Neurology. 2010. Practice parameter: Treatment of nonmotor symptoms of Parkinson disease: Report of the Quality Standards Subcommittee of the American Academy of Neurology. Neurology 74: 924-931. 


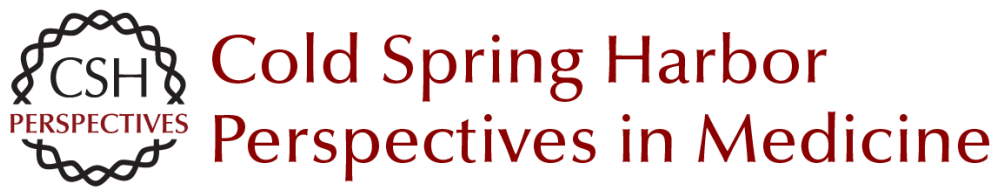

\section{Clinical Approach to Parkinson's Disease: Features, Diagnosis, and Principles of Management}

João Massano and Kailash P. Bhatia

Cold Spring Harb Perspect Med 2012; doi: 10.1101/cshperspect.a008870 originally published online February 21, 2012

Subject Collection Parkinson's Disease

Functional Neuroanatomy of the Basal Ganglia José L. Lanciego, Natasha Luquin and José A. Obeso

Animal Models of Parkinson's Disease: Vertebrate Genetics Yunjong Lee, Valina L. Dawson and Ted M. Dawson

Innate Inflammation in Parkinson's Disease V. Hugh Perry

Parkinson's Disease and Parkinsonism:

Neuropathology

Dennis W. Dickson

Physiological Phenotype and Vulnerability in Parkinson's Disease

D. James Surmeier, Jaime N. Guzman, Javier Sanchez, et al.

Clinical Approach to Parkinson's Disease:

Features, Diagnosis, and Principles of

Management João Massano and Kailash P. Bhatia

The Role of Autophagy in Parkinson's Disease Melinda A. Lynch-Day, Kai Mao, Ke Wang, et al.

Disruption of Protein Quality Control in

Parkinson's Disease

Casey Cook, Caroline Stetler and Leonard Petrucelli

\section{Drosophila as a Model to Study Mitochondrial Dysfunction in Parkinson's Disease Ming Guo}

Parkinsonism Due to Mutations in PINK1, Parkin, and DJ-1 and Oxidative Stress and Mitochondrial

Pathways Mark R. Cookson

Programmed Cell Death in Parkinson's Disease Katerina Venderova and David S. Park

Genomics and Bioinformatics of Parkinson's

Disease

Sonja W. Scholz, Tim Mhyre, Habtom Ressom, et al.

Motor Control Abnormalities in Parkinson's

Disease

Pietro Mazzoni, Britne Shabbott and Juan Camilo Cortés

Parkinson's Disease: Gene Therapies Philippe G. Coune, Bernard L. Schneider and Patrick Aebischer

Functional Neuroimaging in Parkinson's Disease Martin Niethammer, Andrew Feigin and David Eidelberg

Leucine-Rich Repeat Kinase 2 for Beginners: Six Key Questions Lauren R. Kett and William T. Dauer

For additional articles in this collection, see http://perspectivesinmedicine.cshlp.org/cgi/collection/ 